\title{
Splenogenous Malignant Reticulosis*
}

\author{
Takao Fukuda \\ Department of Pathology (Prof. N. Sasano), \\ Tohoku University School of Medicine, Sendai
}

\begin{abstract}
Two cases of particular neoplastic reticulosis of splenic origin were reported. Neoplastic reticulum cells were exclusively proliferated in the Billroth's cords (Case 1) or in the follicles (Case 2) of the spleen and showed the features of diffuse interstitial infiltration and hematogenous dissemination, which indicated leukemia-like process in this disease.

The reticulum cells in other organs, such as the lymph nodes and bone marrow, showed no tendency to proliferation. No feature of the usual leukemia was demonstrated.

Leukemia-like proliferation of reticulum cells may originate from various organs and tissues of the reticuloendothelial system, and such a condition is most appropriately called malignant reticulosis with or without hematological findings.
\end{abstract}

Leukemia of reticulum cell or histiocyte origin has been a matter of much controversy with regard to the problem of the stem cell and to the origin of monocyte. Most of the European and American authors have regarded leukemic reticulosis as monocytic leukemia of the Schilling type, because they believe that monocytes develop from reticulum cells (Amromin ${ }^{1} 1968$, Wintrobe ${ }^{2}$ 1967).

In Japan, however, monocytes have been distinguished from reticulum cells as of an independent origin on account of different morphological and biological characters. A series of monocytes is considered to be of myelogenous origin (Amano $^{3}$ 1942), while histiocytes or reticulum cells do not physiologically appear in the peripheral blood (Akazaki ${ }^{4}$ 1952). Fukuda ${ }^{5,6}(1965,1966)$ and Iijima ${ }^{7}$ (1966) proposed the definition of leukemic reticulosis as diffuse and irreversible proliferation of lymphatic reticulum cells with leukemic dissemination. An aleukemic variety of this disease was also reported and the term 'malignant reticulosis' was applied to the disease entity, consisting in leukemia-like proliferation of lymphatic reticulum cells with or without hematological findings (Fukuda ${ }^{8}$ 1968, Rappaport ${ }^{9}$ 1966).

The cases presented here were characterized by extensive proliferation of splenic reticulum cells with leukemic dissemination and were considered to constitute a hitherto unknown entity that should be called 'splenogenous malignant reticulosis'.

Received for publication, June 21, 1969.

* Presented at the 8th Congress, Japan Society of the Reticuloendothelial System, Sendai, May, 1968. 


\section{Case Reports}

\section{Case 1.}

A 63-year-old Japanese male suffered from hematemesis and transient epigastric pain since 3 months prior to death, and became markedly anemic. He was treated conservatively for gastric ulcer for 1 month but his complaints remained unchanged. The liver was palpable 5 finger-breadths under the costal margin, but no splenomegaly or lymph node enlargement was noticed. At that time blood counts revealed a RBC 269 mills., Hb. 58\%, and a WBC 6,700. Two months later, massive hematemesis and severe abdominal pain appeared suddenly and emergency operation was performed under the diagnosis of perforation peritonitis.

A perforated ulcer, $2 \times 3 \mathrm{~cm}$ in size, was found on the lesser curvature of the stomach. Partial cuneiform resection instead of subtotal gastrectomy was performed because of his poor condition. One month after the operation, pleural effusion appeared on the left side. Accidental injury of an intercostal vein at the pleural puncture resulted in massive hemorrhage leading to collapse and killed the the patient in 8 hours. His last blood count revealed a RBC 277 mills., Hb. $70 \%$ and a WBC 5,300. Other laboratory data were not contributory.

At autopsy, massive coagulated blood, $4,200 \mathrm{ml}$ in total, occupied the whole left pleural cavity.

The spleen, weighing $440 \mathrm{~g}$, was considerably firm and measured $16 \times 9 \times 6 \mathrm{~cm}$. The surface was smooth and fresh red in color. On section, the splenic parenchyma was generally fresh red and the Malpighian follicles were indistinct. No abnormalities were found on the trabecular pattern, but whitish irregular network was visible all over the cut surface. Neither discernible discrete mass nor infarcts were seen (Fig. 1).

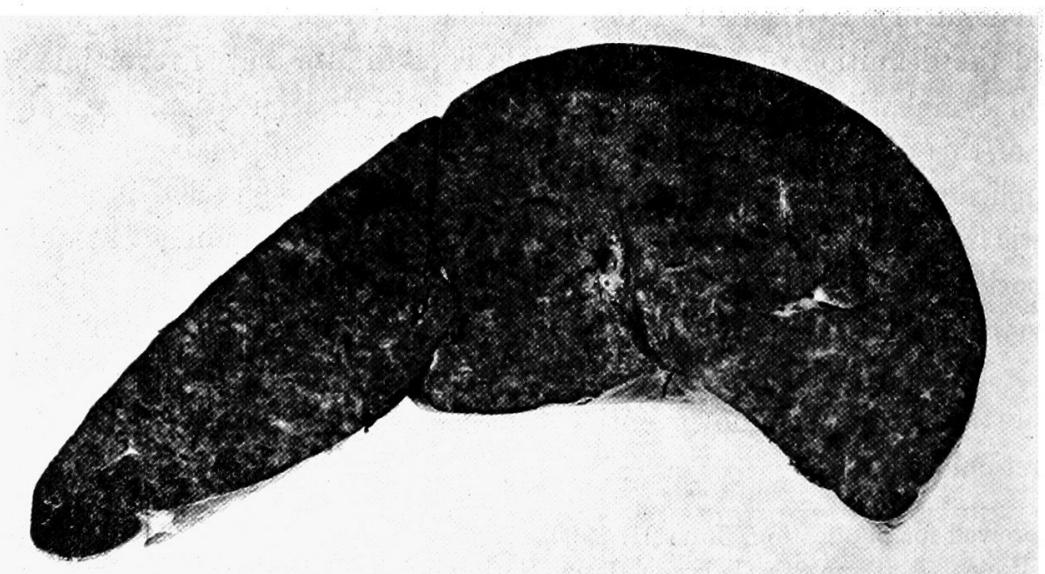

Fig. 1. Spleen (Case 1). 440 g. $16 \times 9 \times 6 \mathrm{~cm}$. Whitish irregular network is visible all over the cut surface. 
The liver weighed $1,840 \mathrm{~g}$ and was markedly anemic without jaundice. A reticular pattern corresponding to the portal areas was distinct uniformly on the cut surface. No abnormality was found in the bile duct system.

All the lymph nodes were not enlarged and soft in consistency. The bone marrow was fatty in the femur. Ribs and sternal marrow were cellular in appearance, but no signs of leukemia were found by macroscopic observation.

Histological examination

Spleen. The Malpighian follicles were markedly atrophic but they were still preserved as aggregation of mature lymphocytes. The Billroth's cords were disarranged with proliferation of various atypical reticulum cells. These cells had oval or deeply indented hyperchromatic nuclei with prominent nucleoli, and irregularly outlined abundant cytoplasma. The sinuses were also distorted and atypical cells were often found protruding across the endothelial lining in a palisade-like arrangement (Fig. 2).

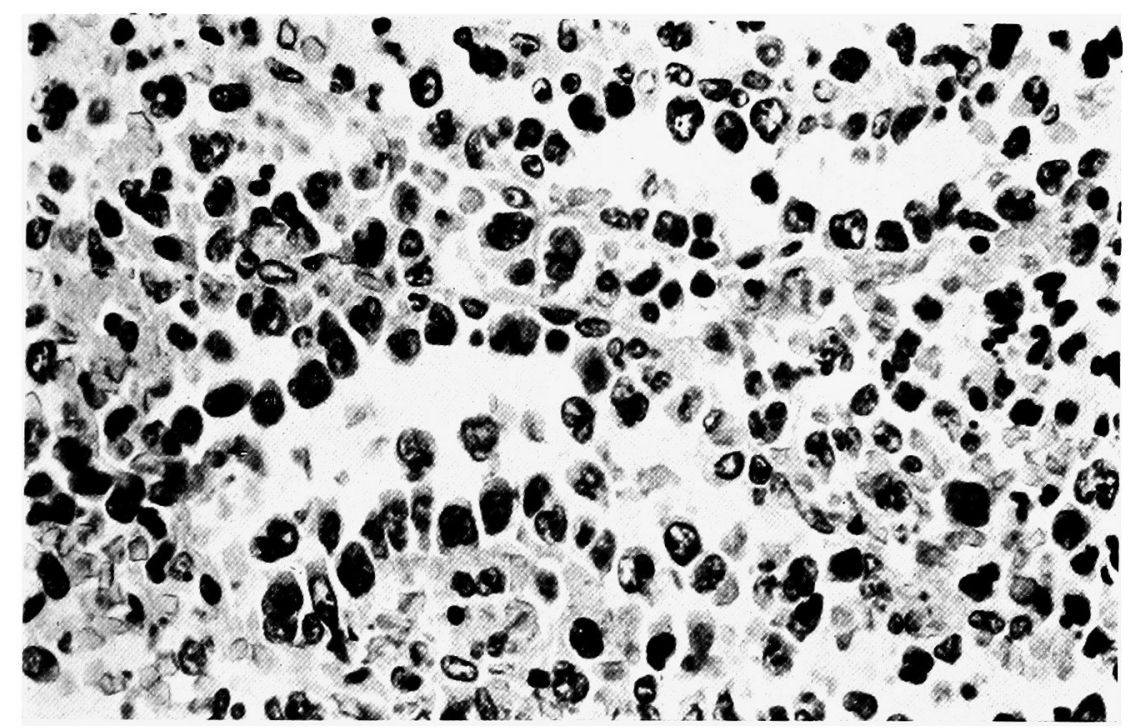

Fig. 2. Various atypical reticulum cells are proliferated in the Billroth's cords and protrude into the sinal spaces. Hematoxylin and eosin. $\times 400$.

It was frequently observed that the atypical reticulum cells, exhibiting marked deformities, e.g., dumb-bell or tadpole shape, were just passing through the meshes of argyrophilic fibers or the endothelial slit (Fig. 3). The sinus endothelial cells showed neither swelling nor a tendency to proliferation. No abnormality was found in venous subintimal spaces.

The architecture of argyrophilic fibers was slightly deranged, but there was no finding indicating portal hypertension.

Liver. Infiltration of the atypical reticulum cells was prominent in the sinusoidal spaces and the portal areas leading to compression of the hepatic 


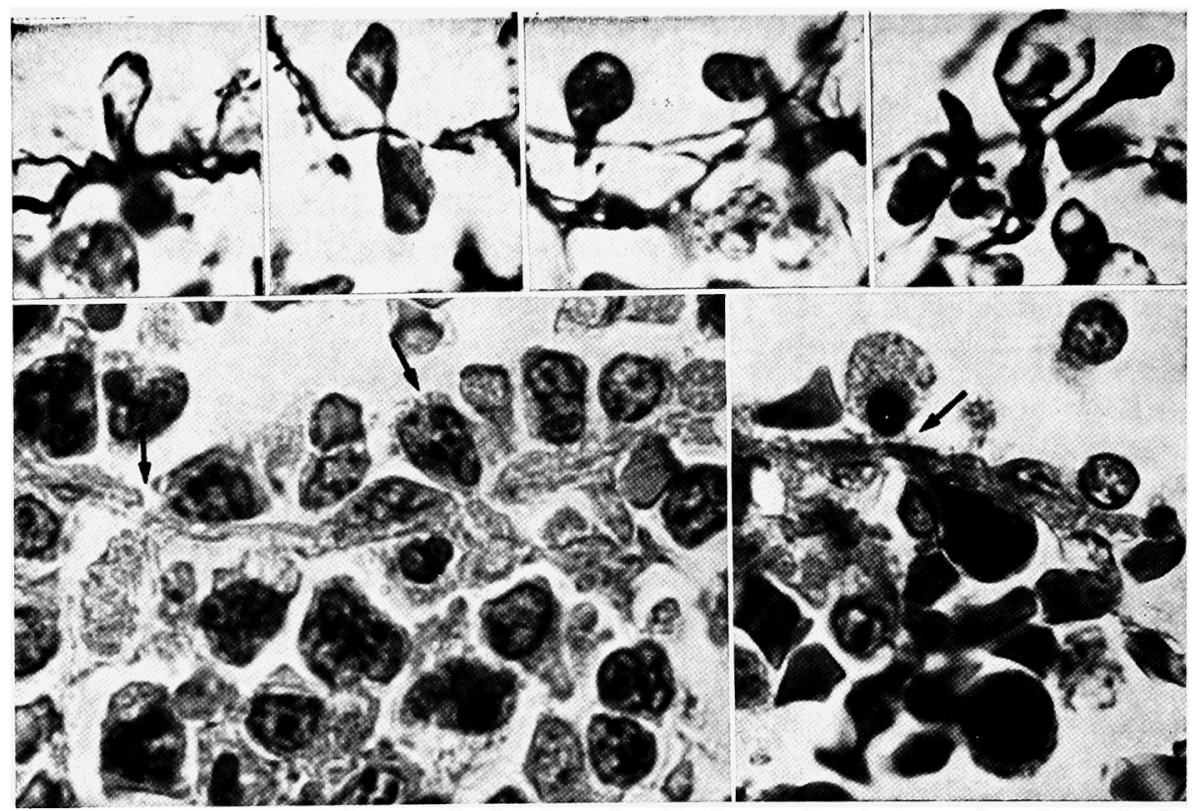

Fig. 3. Top: Dumb-bell or tadpole shaped reticulum cells, just passing through the meshes of argyrophilic fibers. Silver impregnation. $\times 1,000$. Bottom: Protrusion of reticulum cells through the endothelial slit. Sinus endothelial cells show no tendency to proliferation. Hematoxylin and eosin (left), Masson's trichrome (right). $\times 1,000$.

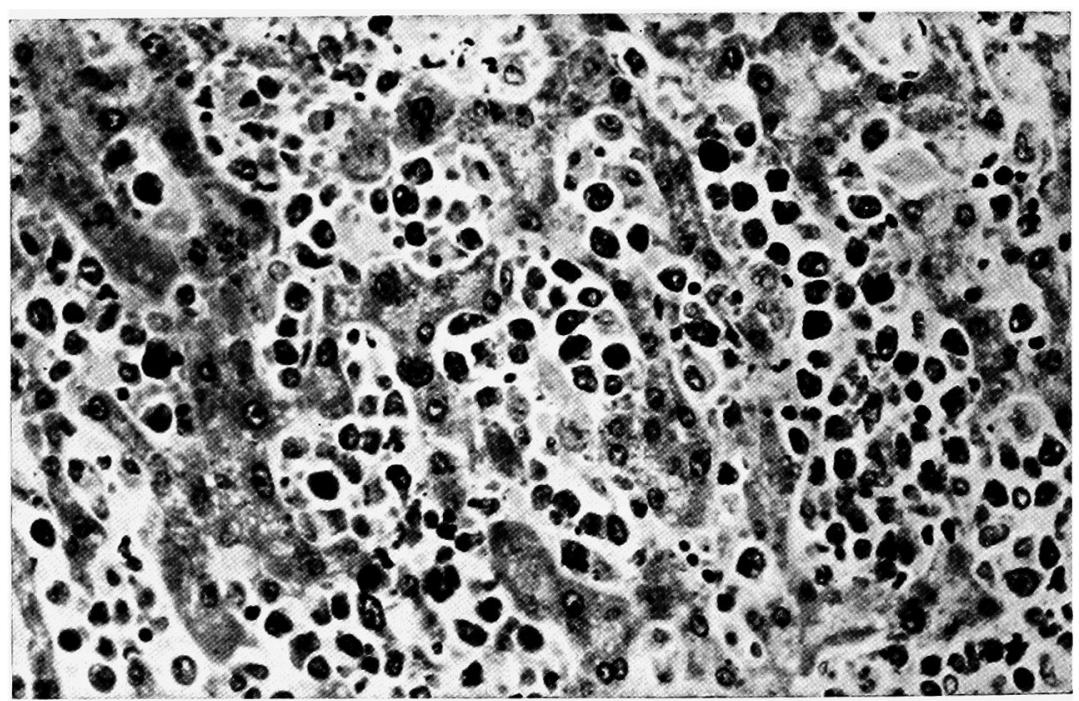

Fig. 4. Infiltration of atypical reticulum cells into the sinusoidal spaces of the liver. Giemsa. $\times 250$.

parenchyma (Fig. 4). Kupffer's stellate cells showed no tendency to proliferation.

Lymph nodes. The basic structures, such as sinus, medulla, and follicle and lymphatic parenchyma were well preserved and no infiltration or metastatic foci were observed, but atypical cells were occasionally found in the capillary lumina. 
Bone marrow. The bone marrow was slightly hypoplastic but showed normal patterns of erythropoiesis and granulopoiesis. Although emboli of atypical cells were observed in small vessels, there was no extensive infiltration of tumor cells or leukemia-like behavior of reticulum cells.

Other organs. The atypical reticulum cells were diffusely infiltrated into the interstitial tissues of various organs such as the kidneys, adrenals, testes and pancreas. These cells were observed in massive emboli in peripheral blood vessels of various organs, particularly in the pulmonary capillaries and glomerular tufts of the kidney, and suggested a leukemic dissemination through the blood stream.

Case 2.

A 66-year-old Japanease female was admitted to the hospital, twelve days prior to death, with chief complaints of edema, anorexia and general malaise.

Liver carcinoma was suspected to be the cause of hepatomegaly. There was severe cachexia, but anemia, jaundice and other abnormalities were not detected. After admission, the liver was gradually enlarged and tenderness appeared in the right hypochondral region. Her general condition became progressively worse and she died after a course of 2 weeks. Blood counts revealed a RBC 500 mills., $\mathrm{Hb}$. $75 \%$ and a WBC 7,800 .

Autopsy revealed hepatosplenomegaly and lymph node enlargement up to a finger-tip size, in the peripancreatic, retroperitoneal and hepatic hilar regions.

The spleen, weighing $340 \mathrm{~g}$, measured $10 \times 6 \times 13 \mathrm{~cm}$ and was firm in consistency. On section, multiple blood cysts or blood lakes (Blutmeer) of irregular shape and white granulomatous nodules of various sizes, both up to $5 \mathrm{~mm}$ in diameter, were scattered throughout the cut surface (Fig. 5). The liver weighed $1,300 \mathrm{~g}$ and

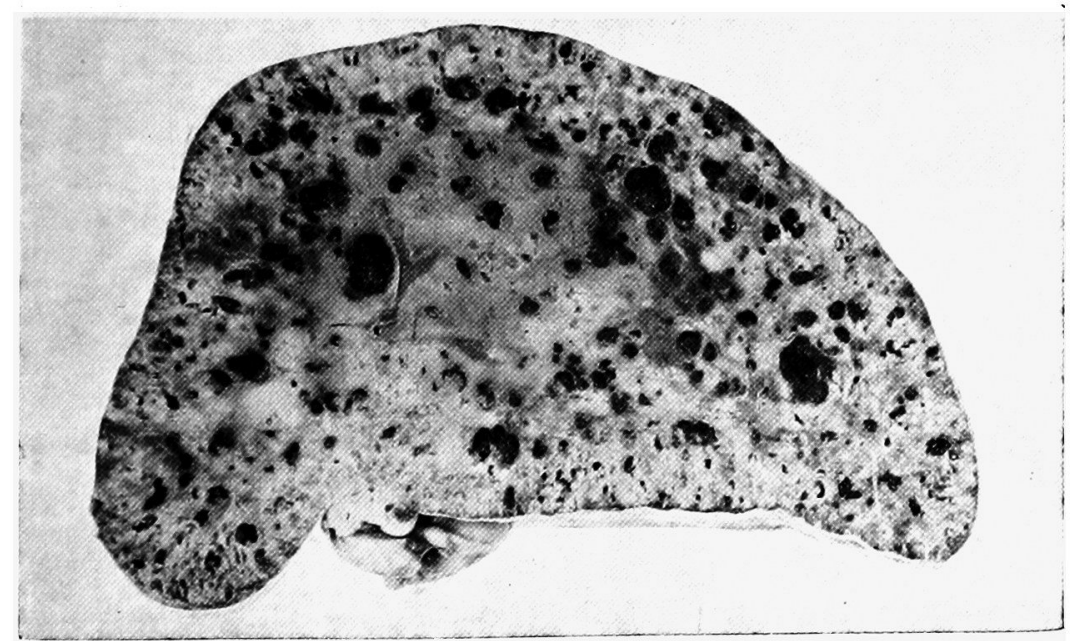

Fig. 5. Spleen (Case 2). $340 \mathrm{~g} .10 \times 6 \times 13 \mathrm{~cm}$. Multiple blood lakes (Blutmeer) and granulomatous nodules of various sizes are scattered throughout the cut surface. 
was markedly anemic; and a reticular pattern corresponding to the portal areas was found all over the cut surface.

The bone marrow was cellular in the sternum but the femoral marrow was almost fatty in appearance.

\section{Histological examination}

Spleen. The basic structure was markedly distorted and the histological feature was characterized by multiple foci of reticulum cell proliferation and blood lakes (Blutmeer) of various sizes and shapes.

All the Malpighian follicles were replaced by a marked proliferation of large atypical reticulum cells with large oval and vesicular nuclei containing one to three nucleoli. Their cytoplasma was scanty and irregular in outline (Fig. 6). No cytoplasmic granulation was observed. They were massively proliferated in the follicles and caused compression and partial fibrosis of perifollicular Billroth's cords. Foci of blood cysts or blood lakes (Blutmeer) were irregularly lined with atypical reticulum cells, but had neither proper endothelial lining nor their own particular

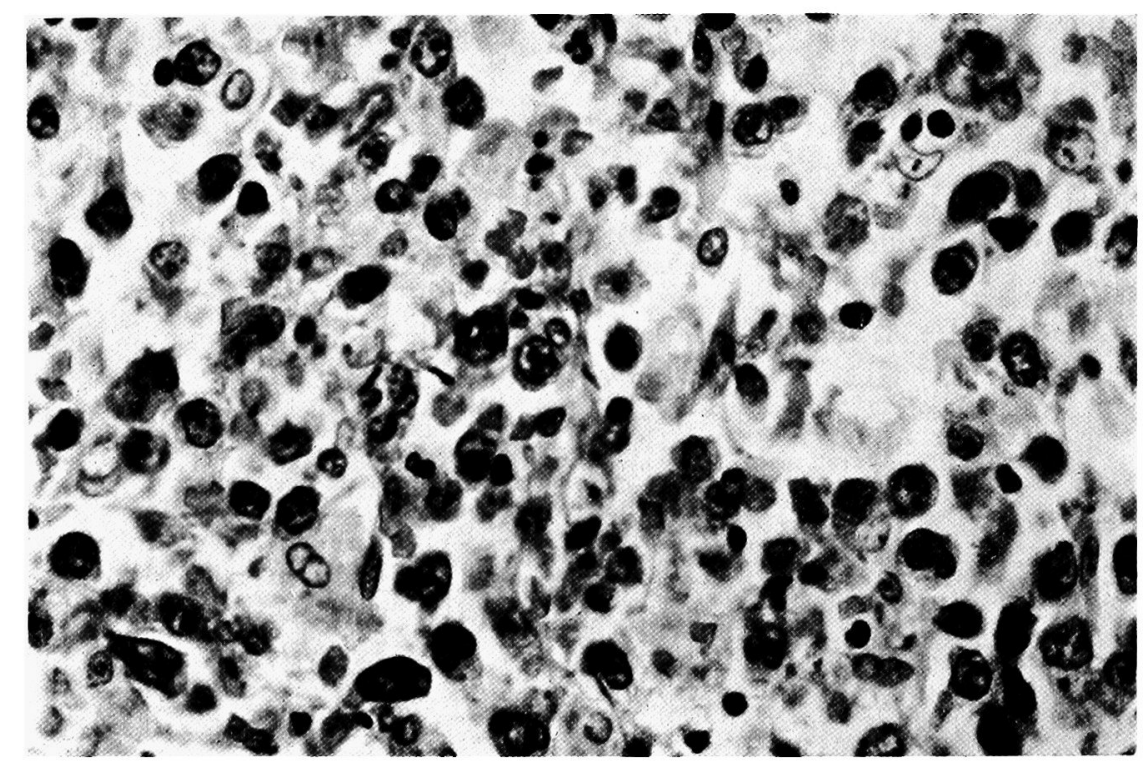

Fig. 6. Proliferation of neoplastic reticulum cells in the follicular sites. Hematoxylin and eosin. $\times 400$.

walls. Small vessels, corresponding to the central arteries of the follicles, were frequently observed in the lumina with a mantle of similar atypical reticulum cells. In some follicles, proliferated reticulum cells were dissociated in various degrees associated with blood invasion from the periphery (Fig. 7).

It was assumed on these findings that tumor cells had once completely occupied the follicles, had been gradually dissociated and carried away, so that blood accumulation in the form of multiple blood lakes had developed. 


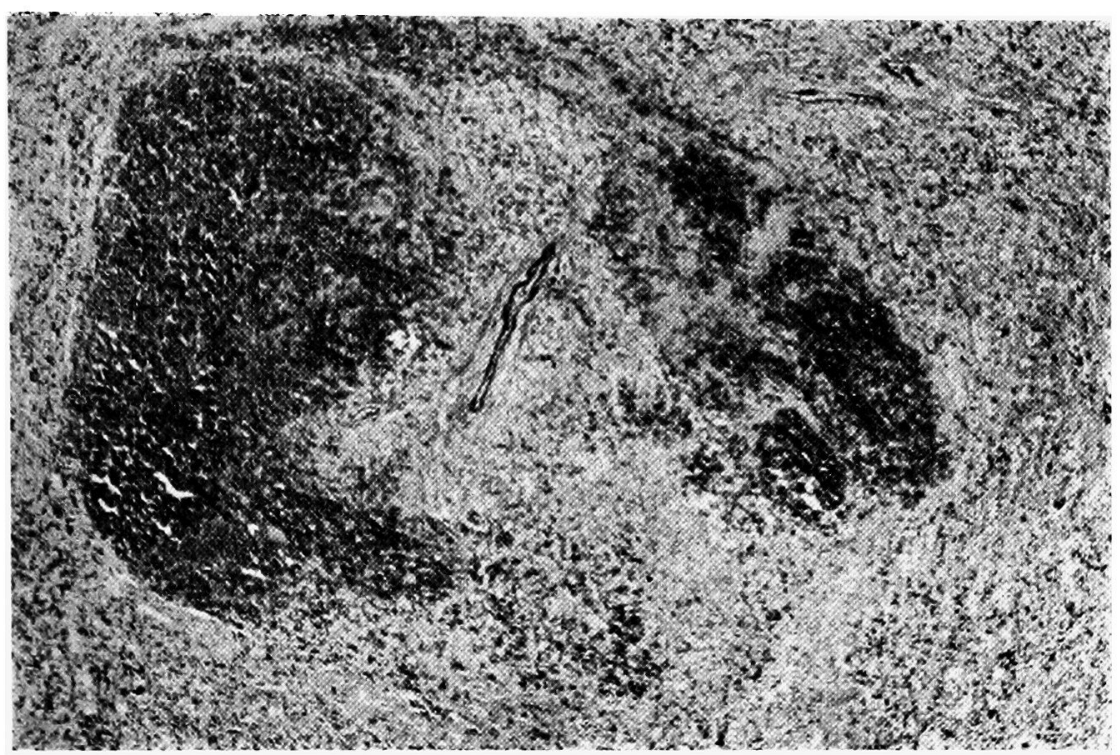

Fig. 7. Irregularly shaped blood lake. The original sites of follicles are displaced by blood lakes. Small vessel, corresponding to the central artery of the follicle, is visible in the central region. Masson's trichrome. $\times 100$.

Liver. Sinusoidal spaces were markedly distended, and atypical reticulum cells similar to those of the spleen were found infiltrating.

Lymph nodes. Enlarged lymph nodes in the retroperitoneal, peripancreatic and hepatic hilar regions had large atypical reticulum cells massively invading the sinal spaces. However, the basic structures of sinus, medulla and follicles were well demonstrated and most of the lymphatic tissues were also preserved. Small lymph nodes from other portions were entirely normal and no evidence of systemic diseases such as lymphosarcoma, reticulum cell sarcoma and leukemia was confirmed.

Bone marrow. Well circumscribed multiple foci of tumor cells, usually miliary in size, were found invading the marrow. Most of the hematopoietic tissues showed a normal pattern of erythropoiesis and granulopoiesis.

Other organs. Massive infiltration of tumor cells was found in the interstitial tissues of various organs, particularly in the kidneys, adrenals and pancreas. Embolism of tumor cells was also observed in the peripheral blood vessels of various organs such as the lung and glomerular tufts of the kidneys.

\section{Comments}

The first case was characterized by diffuse and irreversible proliferation of reticulum cells in the Billroth's cords and leukemic dissemination of these cells 
through the blood stream. No other organs such as lymph nodes and bone marrow could be considered to be the primary site of reticulum cell proliferation.

The second case was that of intensive proliferation of neoplastic reticulum cells in the follicles and subsequent dissociation of these cells with dissemination into the blood stream. Consequently, the spaces of follicles were replaced by blood accumulation in the form of multiple blood lakes.

Unfortunately, hematological analysis was performed in neither case, so that the presence of reticulum cells in the peripheral blood was not ascertained. However, massive embolism of reticulum cells in the peripheral blood vessels and infiltration in various organs were confirmed by postmortal examinations and presented evidence for a leukemia-like character with biological malignancy of the disease.

Primary splenic neoplasms are extremely rare and occupy only $0.64 \%$ of all tumors of the body (Krumbhaar $\left.{ }^{10} 1927\right)$. Hausmann and Gaarde ${ }^{11}$ (1943) and later Gordon and Paley ${ }^{12}$ (1951) summarized all the reported cases and found in total 189 cases of splenic malignant neoplasm. Das Gupta et al. ${ }^{13}$ (1965) collected other 9 cases from 1951 to 1962 and added 10 cases from his own experience. Among these previous reports, hemangioendothelioma or angiosarcoma and reticulum cell sarcoma were frequently observed, but a report of such cases as described in the present study has not yet appeared in the literature.

Concerning the histogenesis, primary neoplasms of the spleen can be divided into the following five groups:

1) Tumors of capsular and trabecular origin

Fibroma

Fibrosarcoma

Leiomyosarcoma

Neurosarcoma

2) Tumors of vascular origin

Lymphangioma

Hemangioma

Endothelioma

3) Tumors of lymphatic tissue origin

Giant follicular lymphoma

Lymphosarcoma

4) Tumors of reticuloendothelial origin

Reticulum cell sarcoma

Hodgkin's disease

'Malignant reticulosis'

5) Tumors of embryonic inclusion origin

Epidermoid cyst

Dermoid cyst

Carcinoma

Mesothelial inclusion cyst 
(Bostick ${ }^{14}$ 1945, Das Gupta et al. ${ }^{13}$ 1965, Gelin and Florès ${ }^{15}$ 1953, Giampalmo et al..$^{16}$ 1963, Harshman et al. ${ }^{17}$ 1961, Hickling ${ }^{18}$ 1964, Isaacson et al. ${ }^{19} 1947$, Smith and Rusk $^{20}$ 1923)

Most of these primary malignant tumors assume solid and nodular features, which are well circumscribed from normal splenic tissues. They are spherical and whitish or 'mutton fat' in appearance and even the metastatic foci exhibit nodular appearance.

Enlargement of the spleen, either due to homogeneous cell proliferation as in Case 1 or by multiple and nodular foci as in Case 2, is usually found as a feature of systemic lymphatic diseases such as lymphosarcoma, Hodgkin's disease and reticulum cell sarcoma (Ahmann et al. ${ }^{21}$ 1966). There was no evidence of such systemic disease process in the present cases.

The findings of neoplastic reticulum cells, most intensively proliferating in the Billroth's cords (Case 1) and in the follicles (Case 2) of the spleen, support their splenic origin. Furthermore, diffuse interstitial infiltration of such cells in various organs and findings indicating hematogenous dissemination demonstrate a leukemia-like character of these splenic reticulum cells. The reticulum cells in the other tissues such as the lymph nodes and bone marrow showed no tendency to proliferation.

A disease with pronounced appearance of neoplastic reticulum cells in the peripheral blood has long been known under various names of 'leukemic reticuloendotheliosis', 'leukemic reticulosarcomatosis', 'monocytic leukemia', 'histiocytic leukemia', and 'réticulose histiomonocytaire'. However, the concept, clinical and pathological features and diagnostic criteria have been poorly defined and controversial.

Fukuda ${ }^{5,6}$ (1965, 1966) and Iijima ${ }^{7}$ (1966) reviewed most of the Japanese cases and proposed the definition of leukemic reticulosis by irreversible proliferation of lymphatic reticulum cells with hematogenous dissemination. The disease is characterized by 1) diffuse proliferation of reticulum cells in the medulla of lymph nodes without destruction of their basic structure, 2) diffuse infiltration of reticulum cells in various organs, 3) leukemic reticulum cells appearing in the peripheral blood, 4) acute leukemia-like symptoms and 5) a rapidly fatal clinical course of 4-6 months duration. The existence of an aleukemic variety was also acknowledged and the term 'malignant reticulosis' was applied to the disease with irreversible proliferation of lymphatic reticulum cells with or without hematological findings (Fukuda ${ }^{8}$ 1968, Rappaport ${ }^{9}$ 1966).

But in the present cases, primary proliferation of reticulum cells was found exclusively in the spleen, not in the lymph nodes, and it seems reasonable to call such conditions 'splenogenous malignant reticulosis'. Although reticulum cells distribute in various organs and tissues, the origin of their leukemia-like proliferation may be confined to certain organs, such as the lymph nodes, spleen, bone marrow, and skin. In observed cases, lymphatic type is extremely prevalent but 
attention must be also paid to the existence of splenogenous, myelogenous and cutaneous types. Ohnishi and Saito ${ }^{22}$ (1968) reported two cases of leukemic reticulosis in which the bone marrow seemed to be the primary site of reticulum cell proliferation. Similar cases of cutaneous origin were reported by French schools (Cazal ${ }^{23}$ 1952), and the nature and pathological findings of Sézary's syndrome as well as mycosis fungoides should be reexamined from the viewpoint of this malignant reticulosis.

In the present report, the author assumes the existence of malignant reticulosis of splenic origin, a hitherto unknown type of the disease. The primary site of the cell proliferation may be located either in the follicle or in Billroth's cords.

\section{References}

1) Amromin, G.D. Pathology of Leukemia, New York, Hoeber 1968.

2) Wintrobe, M.W. Clinical Hematology, 6th ed., Philadelphia Lea and Febiger, 1967.

3) Amano, S. Über die Monocytenreihe. Acta haemat. jap. (Jap.), 1942, 6, 269-291.

4) Akazaki, K. Reticuloendothelial system. Acta path. jap., 1952, 2, 113-147.

5) Fukuda, T. Leukemic reticulosis and allied disorders. Tohoku J. exp. Med., 1965, 87, 1-34.

6) Fukuda, T. Leukemic reticulosis. J. reticuloendoth. Soc., 1966, 3, 117-134.

7) Iijima, S. Lenkemic reticuloendotheliosis. Tohoku J. exp. Med., 1966, 89, 35-44.

8) Fukuda, T. Malignant reticulosis. Tohoku J. exp. Med., 1968, 94, 351-361.

9) Rappaport, H. Malignant histiocytosis. In: Tumors of the Hematopoietic System, ed. by AFIP, Washington D.C. 1966, pp. 49-63.

10) Krumbhaar, E.B. The incidence and nature of splenic neoplasms with a report on forty recent cases. Ann. clin. Med., 1927, 5, 833-860.

11) Hausmann. P.F. \& Gasrde, F.W. Malignant neoplasms of the spleen; Review of the literature and report of a case of primary lymphosarcoma. Surgery, 1943, 14, 246-255.

12) Gordon, J.D. \& Paley, D.H. Primary malignant tumors of the spleen; Statistical review and report of a cass of a primary lymphosarcoma. Surgery, 1951, 29, 907-913.

13) Das Gupta, T., Coombes, B. \& Brasfield, R.D. Primary malignant neoplasms of the spleen. Surg. Gynec. Obstet., 1965, 120, 947-960.

14) Bostick, W.L. Primary splenic neoplasms. Amer. J. Path., 1945, 21, 1143-1165.

15) Gelin, G. \& Florès, R. Les tumeurs primitives de la rate. Sang, 1953, 24, 77-95.

16) Giampalmo, A... Antoci, B. \& Farina, P. La patologia angiomatosa della milza e del fegato. Pathologica, 1963, 55, 1-60.

17) Harshman, J.A., Smith. E.B. \& Evans. P.V. Cystic lymphangiectasis of the spleen. Arch. Path., 1961, 71, 344-348.

18) Hickling, R.A. Giant follicle lymphoma of the spleen. Brit.med.J., 1964, 2, 787-790.

19) Isaacson, N.H., Spatt, S.D. \& Grayzel, D.M. Primary spleaic Hodgkin's disease without lymph node involvement. Ann. intern. Med., 1947, 27, 294-301.

20) Smith, C.E. \& Rusk, G.Y. Endothelioma of the spleen; a study of two cases with review of the literature of primary malignancy of the spleen. Arch. Surg., 1923, 7, 371414.

21) Ahmann, D.L., Kiely, J.M., Harrison, E.G., Jr. \& Payne, W.S. Malignant lymphoma of the spleen. A review of 49 cases in which the diagnosis was made at splenectomy. Cancer (Philad.), 1966, 19, 461-469.

22) Ohnishi, Y. \& Saito, H. Two autopsy cases of leukemic reticulosis. Proc. Jap. Soc. RES (Jap.), 1968, 8, 81-89.

23) Cazal, P. Aspects cliniques et hématologiques de la réticulose maligne. Acta haematol., $1952,7,65-85$. 